\title{
Bilateral Sensorineural Hearing Loss in Childhood - Three Cases Presenting in British Forces Germany
}

\author{
Lt Col S A St J Miller \\ MSc, MFCM, MRCGP, RAMC \\ Specialist in Community Medicine (Child Health) \\ British Military Hospital, Rinteln.
}

SUMMARY: Three cases of bilateral sensorineural deafness detected at various stages of childhood in British Forces Germany (BFG) illustrate the importance of providing appropriate audiological screening for all children in the Services and multidisciplinary assessment for any child with suspected developmental delay.

\section{Introduction}

Amongst children in the United Kingdom, the prevalence of hearing loss of sufficient severity to require the use of hearing aids is approximately two per $1000^{1}$. The hearing loss may be conductive or sensorineural or a mixture of both. When the hearing loss is sensorineural it usually results from dysfunction of the cochlea although disorders of the auditory nerve and central nervous system do sometimes occur ${ }^{2}$.

Sensorineural hearing loss has an incidence of between one and two cases per 1000 live births ${ }^{3}$. There are many causes. It may be familial or result from drugs or infection, especially rubella, during pregnancy and there are many rare syndromes which include sensorineural hearing loss. Perinatal causes include severe hypoxia during delivery and hyperbilirubinaemia. Meningitis and some of the common childhood infections such as mumps and measies can also result in sensorineural deafness ${ }^{4}$. In a third of cases no cause will be found and it is in these children that detection may be most difficult because the problem cannot be anticipated. In some cases of unknown aetiology the condition is not present at birth but starts to develop later in childhood.

Since there are approximately 4,000 births per annum in BFG at least four children born each year could suffer from sensorineural hearing loss. These children need to be recognised as soon as possible in particular because successful management may depend upon early diagnosis. Although the degree of benefit remains a contentious issue in that there is no proof that very early detection affects the outcome in these children, it was nevertheless the verdict of the Joint Working Party on Child Health Surveillance recently that there were good theoretical reasons for expecting the prognosis to be improved ${ }^{5}$.

The three cases of bilateral sensorineural hearing loss described below were cases identified from one half of the child population in British Forces Germany during a twelve month period and they illustrate some of the ways in which this problem presents in childhood.

\section{Case 1}

A 16 month old girl was investigated for possible hearing loss after failing the distraction screening test performed by the health visitor when she was 9 months old. Further investigations did not immediately follow her failure of this screening test because she had appeared to be making noises appropriate for her age. During a later medical consultation for urinary tract problems her mother, a trained nurse, expressed concern about her daughter's failure of the screenin test although neither she nor her husband reall suspected a problem.

Electric response audiometry (ERA) was arranget? and performed under light sedation in the departmen's of physiological measurement at the British Militar Hospital, Rinteln. The result showed no definite wave $\bar{\partial}$ response below $80 \mathrm{~dB}$ on either side. Normally a wave response can be evoked with stimuli as low as $30 \mathrm{~dB}$.

There was nothing in her past medical history to account for such a severe degree of bilateral hearing loss. Following an uneventful prenatal period she had been delivered at term by elective Caesarian section because her mother had had a previous Caesarian section. The birth weight was $4.390 \mathrm{kgs}$, the Apgar was satisfactory and the neonatal period uneventful. There was no family history of hearing problems.

Because of the absence of facilities in BFG to manage this child, she was repatriated with her family to their city of origin. Hearing aids have been fitted and she is under the care of the local services for children with impaired hearing. The latest reports on her progress are encouraging.

\section{Case 2}

A 27 month old girl was referred for developmental assessment because of the speech therapist's concern over her poor language development. She had been born at 37 weeks gestation with no apparent abnormalities apart from a congenital right cataract. During pregnancy her mother had been in contact with rubella infection but was already immune. The delivery 
was normal and the Apgar satisfactory. She was referred to the eye department because of her congenital cataract but no other investigations were performed at this stage. The family medical history included a cousin who was reported to suffer from sensorineural deafness.

She was referred to the paediatric department at 6 months of age because of concern on the part of the general practitioner over her poor head control. Her development was subsequently monitored in the paediatric department and it appeared to be progressing normally except that at 18 months of age she still had no meaningful words.

At developmental assessment her motor development was found to be appropriate for age but she had no recognisable words at all and indicated her needs with squeals. Although playing normally for her age with miniature toys she gave no evidence of any verbal comprehension. ERA revealed a threshold of $50 \mathrm{~dB}$ for the left ear with no response whatever in the right ear.

Because the family were due to visit relatives in Scotland shortly after the diagnosis was established, arrangements were made for her to be seen in the audiology department at the Hospital for Sick Children in Edinburgh. The findings were confirmed at that time and the family was advised to remain in Scotland so that a hearing aid could be fitted and regular instruction offered by a teacher of children with hearing impairment.

\section{Case 3}

A five year old boy was referred for developmental assessment at the British Military Hospital in Berlin so that his special educational needs could be recorded according to the requirements of the Education Act of 1981. He was attending the special educational unit at the local primary school because of his poor progress.

His past medical history had been uneventful. He was born by normal delivery in the British Military Hospital at Hannover. His mother required surgery to remove an ovarian cyst at 16 weeks gestation but otherwise the pregnancy was uneventful. There was no family medical history of congenital hearing problems although his mother had suffered from recurrent mastoid infections.

At the developmental assessment (performed when he was five years and four months) his motor development appeared to be appropriate for age as were his drawing skills. On clinical testing he appeared to have a significant hearing deficit. Although his non-verbal comprehension appeared normal, his expressive language was virtually unintelligible and his verbal comprehension was severely impaired. He found difficulty responding to whispered instructions particularly when prevented from lip reading. His social development was appropriate for age but his mother commented that he tended to be a disobedient little boy who had little road sense.

Assessment had shown areas of delayed development which were consistent with hearing impairment and normal intelligence. He was therefore referred urgently to the audiology department and tests were arranged at the Kinderkrankenhaus in Berlin. He was found to have severe bilateral sensorineural hearing loss with chronic serous otitis media.

It was possible to have him fitted with hearing aids in Berlin but expert advice on the management of children with hearing impairment was not available. The introduction of hearing aids appeared to cause a $\frac{5}{5}$ deterioration in his behaviour presumably due to the increase in extraneous noise with which he was now confronted. He was therefore referred for further investigation to the audiological department at is Manchester University as this was in the vicinity of $\overrightarrow{0}$ extended family support. Following thorough testing at $\overrightarrow{.}$ the university it was concluded that the degree of his hearing loss was more severe than had been appreciated in Berlin and arrangements have now been made for him to be fitted with more powerful hearing aids and a radio hearing aid system. It is hoped that the family will be $\vec{\omega}$ able to remain in Berlin although the absence of a teacher trained specifically in the management of this problem makes it likely that repatriation will become $\dot{\sigma}$. necessary in due course.

\section{Discussion}

These three cases of sensorineural deafness childhood illustrate different ways in which the problen may become apparent and how easily detection can be delayed. The first case demonstrates the value of the distraction test as a screening procedure during the fir year of life providing that those failing the test axe properly investigated ${ }^{6}$. In the second case the problem was detected after significant speech delay had been recognised. The fact that the poor educational progress of the child in the third case was wrongly attributed to low intelligence emphasises the importance of comprehensive assessment when any developmental problem is suspected.

The strategy used to achieve early detection of hearing impairment varies between health districts in the United Kingdom. In some areas comprehensive screening in the neonatal period has been adopted using the auditory response cradle but this needs considerable organisation and is extremely costly in terms of manpower ${ }^{7}$. This would not be appropriate in BFG at the present time but the use of ERA to exclude sensorineural hearing loss in children considered to be at increased risk might be advantageous. Electric response audiometry was used to establish the diagnosis 윽 in two of the cases described in this paper and could be used for all high risk cases such as those with a family history of deafness, suspected intrauterine infection, congenital abnormalities of the head and neck, birthweight below $1500 \mathrm{gms}$, bilirubin levels in excess of 20 mgs per $100 \mathrm{mls}$ during the neonatal period, and after $\mathrm{N}$. neonatal septicaemia or meningitis ${ }^{2}$. A study is currently 
investigating whether a policy of selective screening would be appropriate for BFG.

Most health districts in the United Kingdom use the distraction test in the first year of life and sweep audiometry between the age of four and eight years of age as their main audiological screening strategy ${ }^{8}$. In BFG the distraction test is performed on all children between the ages of seven and nine months but it has not yet been possible to offer routine audiometry to school children in all areas.

Recently parents in BFG have been encouraged to participate in this aspect of child health surveillance by the issue of hints on how to detect hearing problems in their children during infancy. These hints were devised by McCormick in Nottingham and include the failure of the infant to respond to various types of sound at various stages during the first year of life. In fact the suspicion of a parent about possible hearing impairment in a child should be taken seriously at any age ${ }^{2}$.

\section{Conclusion}

The large number of children in BFG and the relatively high annual birth rate make it essential to adopt a cohesive strategy for detecting sensorineural hearing loss as early as possible. The distraction test in the first year of life should continue to be part of this strategy together with audiometry for all children at school entry ${ }^{5}$. There may also be a case for using ERA on those children considered to have been at increased risk of hearing loss and it is hoped that further research will determine whether this is so.

It is not currently possible to manage, within BFG, the majority of children with such severe hearing impairment in the absence of the considerable range of expertise required. As well as needing to be fitted with appropriate hearing aids and radio hearing aid systems, most of these children need continuing supervision from specially trained staff who are not available in BFG. In fact because such children usually have to be repatriated there are not sufficient numbers in BFG to justify the provision of a peripatetic advisory teacher of the hearing impaired although such a person would be invaluable for those who do remain. Two of the three families discussed in this paper have already returned to the United Kingdom and this will often be necessary despite the considerable domestic turmoil and career limitations which ensue.

The most urgent issue is not whether it will ever be feasible to manage all children with sensorineural hearing loss in BFG but how the early detection of the disorder can be achieved so that these children are given the opportunity to reach their full potential.

\section{Acknowledgements}

I would like to acknowledge the expertise in the examination of children shown by WO2 S C Holmes using ERA in the Department of Physiological Measurement at the British Military Hospital, Rinteln.

\section{REFERENCES}

1. Hosking G and Powell R. Chronic Childhood Disorders. Bristol: Wright, 1985.

2. SNashall S E. Deafness in Children. BrJ Hosp Med 1985; 33: 205-209.

3. Martin J A M and Moore W J. Childhood deafness in the European Community. Commission of the Europea Communities. London: HMSO, 1979.

4. NEWTON V E. Aetiology of bilateral sensori-neural hearin loss in young children. J Laryngol Otol 1985; Suppl 19 16-17.

5. HALL D M B. Health for All Children. Report of the Joing Working Party on Child Health Surveillance. Oxfor $\$$ 1989.

6. MCCORMICK B. Hearing screening by health visitors; critical appraisal of the distraction test. Health Visit 1983; 56: 449-451.

7. Hall D M B and Garner J. The feasibility of screening all $\stackrel{\circ}{\Phi}$ neonates for hearing loss. Arch Dis Child 1988; 63: $652-653$.

8. Stewart-Brown S L and Haslum M N. Screening for hearing loss in childhood: a study of national practice. $\mathrm{Br}$ Med $J$ 1987; 294: 1386-1388. 